\title{
New Growth Theories and Trade Liberalization: Measurement of Effects of Technology Transfer on Pakistan's Economy
}

\author{
Dr.Nadeem Bhatti \\ Head of Faculty, North American College \\ 730-Yonge Street, Suite No. 207, Toronto, Ontario, M4Y 2B7, Canada
}

Dr.Muhammad Aamir

Assistant Professor

IER-University of the Punjab-Lahore

Dr.Namatullah Shah

Assistant Professor

Department of Public Administration, University of Sindh-Jamshoro, Pakistan

Muhammad Saleem Rahpoto

Assistant Professor, Deptt: of Economics, Shah Abdul Latif University-Khairpur, Pakistan

Faiz Muhammad Shaikh

Assistant Professor, SZABAC-Dokri-Larkana-Sindh-Pakistan

E-mail: faizanmy2000@hotmail.com

Received: March 16, 2011

Accepted: April 2, 2011

doi: $10.5539 /$ mas.v5n3p85

\begin{abstract}
This study works on the issues of liberalization effects on growth, various theories of growth and bond among liberalization from theoretical and estimation perspectives. Estimation proposes critical examination of renowned economists, their estimation procedure and variable selection is highlighted. This study in the light of Lucas, Barro, Romer and Edwards work develop variables for analysis and used time series which have not used by the scholars especially with reference to Pakistan and its neighboring countries. Empirical literature in 1990's depicts the importance of the trade as major policy variable. Trade openness affects efficiency and growth increase market size, leads to technological spillover, economies of scale through research and development, higher profit to investors. Major objective of study is to explore the bond among liberalization and growth, convergence in Pakistan and its neighboring countries affects of knowledge gap (used for convergence) in selected countries, role of trade distortion and intervention in determining growth process. The variables have depicted the expected signs and most of them are significant at conventional levels. Moreover, $\mathrm{R}^{2}$ in all the estimated regression is considerably high indicating that the empirical model is capable of explaining variability in growth rate of GDP per capita. Moreover, the F statistics values are also significant which shows the efficiency and correctness of model.
\end{abstract}

Keywords: New growth theories, Trade liberalization, Economy

\section{Introduction}

Economic liberalization is getting importance in recent literature throughout world. Firms which have different technological capabilities in same industrial sector or which have different type of institutions in same regions may respond in a diverse manner to the competitive environment developed for the exclusion of barriers to entry during liberalization period. Liberalization may be effects asymmetrically; some firms may advantage whilst others looses, leading to developing within industry deviation in industrial execution. Father of economics 
Adam Smith (1776) who firstly pointed out that International trade has positive effects on economic growth. This idea dominated till world till WWII. Protectionist EG had found substances in Latin America during 60's. Failure of those experiments and relationship of quick EG with the liberalization of IT and the consequent, specialization in different countries, resultant many studies based on the neoclassical growth theories give decisive role to IT as driving force EG. Trade liberalization has occupied an important place in literature debate for a prolonged period. Indeed, the vigor and interest characterizing the debate reflect its importance and continued elusiveness in setting the main contentious issue on the theoretical and empirical fronts. Trade openness is one of the most important determinants of the economic growth, is becoming popular with the each passing day.

Historically, if we analyze the different periods, from import substitution policies to modern time's the dominance of the World Trade Organization (WTO). It is observed that different trade policies were followed in the different time periods. The import substitution period 1960s and 1990s, the liberalization became the fashion of the time.

The import substitution got the spur from the infant industry argument and was promoted by the Rual Prebisch $(1950) .{ }^{2}$ Throughout this epoch, most of the economist follows the protectionist thought and devoted massive time to design models that reliance deeply on the import substitution design. While over the time various economists have altered their viewpoint and empirically studied the consequences of other trade strategies ${ }^{3}$. The researchers used different methodological standard and historical and statistical evidences argued that there are plentiful evidences recommending that more open and outward oriented economies had performed better then the countries pursuing protectionism.

At the moment after the breakdown of the import substitution phenomena and by the development of new generation of growth theories which based upon economies of scale, human development and endogenous technological progress. These expansions have yet again caused trade liberalization into focus. It has produced new evidences of fundamentals which show the way to believe that trade and other policies variables are very important and they significantly affect long run economic growth. ${ }^{6}$ Solow (1956) and others developed new growth models which enlightened that technological changes are exogenous and unaffected by a country integration to world trade. Trade policy reforms are very important and influence the long run economic growth of a country via technological change. Hence, the new growth theories strengthen the idea that the trade as a major source for managing higher and faster growth rates. Moreover, it is also empirically confirmed by Barro (1991) and Gundlach (1997) that those countries which are more open tend to congregate too quick towards their steady state growth path as compared to those which are following protectionist trade regime.Gross and Helpman (1991) and Edwards (1992) have taken a different perception of emphasizing the role of trade openness in smaller countries to adopt technology developed in the advanced nations at a faster rate and thus to grow faster than others having a low degree of openness. What is particularly interesting about this model is that under plausible conditions liberalized economies will grow faster than more restricted once even in the long run. Despite all these developments the relationship among trade openness and growth is yet not be fully resolved. The generalization of results form dynamic equilibrium growth setting presents some problems. Only endogenous growth models have attempted to solve this dogma. Other side the empirical work on the subject is scare and it has been difficult to compose adequate and strong measurements of trade dependence while using time series data. Moreover, robustness of the results and the cross sectional data limitations are problems in this process.

1) Measures of Openness In the international trade theories two types of measures of openness have been used; incidence based measure of individual indicators and outcome based measures. Incidence based measures are the direct indicators of trade policy such as tariff rate, quantitative restrictions, export taxes, and foreign exchange restrictions. The problems with this an approach is the changes in one indicator are not easily weighted against the changes in other. Thus, if average tariffs rises, but export taxes also falls, then it is not clear whether the regime has become more neutral. Due to the flaws in the incidence-based measures of individual indicators, outcome based measures are widely used because they implicitly cover all the sources of trade distortion and based on data which are more promptly available.

\section{2) Openness Ratio}

The openness ratio in its simplest form is the ratio of imports plus exports as a fraction of GDP.

3) Pitchet Index

This is obtained by regressing the trade intensity, defined as the ratio of imports plus exports to GDP, total population, total area, GDP per capita, GDP per capita square. The regression equation is mentioned as under. 
$\mathrm{TI}=\alpha_{\mathrm{o}}+\alpha_{1}$ POP $+\alpha_{2}$ AREA $+\alpha_{3}$ GDPPPC $+\alpha_{4}(\text { GDPPC })^{2}+\varepsilon$

The residuals from the above regression will be taken to measure the degree to which the ration deviates from what it would "normally" be.

4) Measure of Distortions in Prices

To find distortionary effect only one measure used here to capture the effect in price. Since the Dollar (1992) has developed this index, it is known as the best index for measuring the distortions in the economy as compare to Leamer Index (1988). Dollar developed index is used to measure the price distortions. This index is a modified version of an early developed index of relative price levels given by Summers and Heston for international comparison of prices.

$\mathrm{RPLi}=100 *$ ei Pi / Pus

Where is nominal exchange rate between country I an United States (US) and Pi and Pus are their respective price levels. This index, in effect, measures the degree of real exchange rate distortions. The assumption is that if purchasing power parity holds, then the absence of trade barriers and in the absence of non traded goods, RPL $=$ 100 . Deviation from 100 represents either the effects of trade barriers or the effect of non-traded goods. In order to remove the effects of non traded goods that following regression will be estimated.

$\mathrm{RPL}^{\mathrm{i}}=\alpha_{0}+\alpha^{\mathrm{I}} \mathrm{GDPCi}+\alpha \mathrm{DENSi}+\varepsilon \mathrm{I}$

Where, GDPPC is GDP per capita and DENS is population density, these variables are proxies for endowments of capital, land and labor. The assumption is that relatively labor abundant countries will have relatively low prices for non- traded goods, since these tend to be labor intensive. The ratio of actual to predicated RPLi given the degree of distortion (Dollar). Keeping in view above discussion about the methodology, this study is a continuation to ascertain the work empirically proved by known economists D.Romer (1990) and Lucas (1988). This study is on age from other methodologies on the new endogenous growth theories because it is also capturing the impact of trade policy variables like trade distortions and trade interventions indexes which applied by Sabatin Adward and omitted by others. The methodology describes the channel by which trade impacts on the growth via the domestic increased innovation, the technological development accruing in the South Asian countries and rest of the world. Finally, it shows that by controlling other variables whether trade will lead to converging South Asian countries to the advanced economies. Moreover, it is mentioned that catch up affect, distortions impact and intervention affect on economic growth in selected South Asian countries is addition to work on these economies. So it can be counted as contribution of the appropriate methodology for explaining convergence through trade.

\section{Variables and equations.}

\subsection{Gross Domestic Product Percapita (GDPPC)}

The variable GDP per capita (GDPPC) accomplished from WDI. The GDP at 1996 constant prices is taken and is divided by total population to get GDP per capita.

GDP PER CAPITA=(GDP(\%/TOTAL POPULATION $)$

This formula of growth rate is used to attain the growth rate

Growth rate $=($ GDPt- GDPt-1) $/$ GDPt-1

Gross Domestic Investment (GDI)

Values derived from WDI at constant 1995 prices and its growth rate also calculated.

Knowledge Gap (GAP) using GDP at 1995 base year prices. This is proxy variable used for finding catch up affect. This is achieved form ratio of initial GDP to current GDP

$\mathrm{GAP}=($ Initial GDP/ Current GDP)

The Research and Development (RD) used as proxy for finding the catch up affect. This variable included no of Scientists, Engineers and Technicians per million for constructing RD.

\section{Results and Discussion}

Almost all the equations have produced satisfactory and significant results. The variables have depicted the expected signs and most of them are significant at conventional levels. Moreover, the $\mathrm{R}^{2}$ in all the estimated regressions is considerably high indicating that the empirical model is capable of explaining variability in growth 
rate of GDP per capita. Moreover, the F Statistics values are also significant which shows the efficiency and correctness of the model.

Relationship between openness and intervention indexes and economic growth is discussed then important variables which have major contribution towards growth are discussed, like human capital, Foreign Direct Investment, Political Instability and government size.

\subsection{The effect of Openness and Intervention indexes}

The estimated equation (32) has expected sings. The variables are statistical significant except investment (GDI) fro Srilanka. Anyhow, it is also maintaining the expected positive sign. The reason for to be insignificant could be that the countries that have pursued the inward looking policies or policies that have not encouraged local investment through suffocating regulation, it has caused distortionary effects on the investment and make it less effective, as compared to other South Asian countries. Sinha and Sinha (1996) have extracted the same results for Myanmar, India and Bangladesh. The results mentioned in the table 1 takes the case where trade openness (TOP) variable is used as indicator of commercial policy. Moreover, the detailed openness indexes series calculated for all the selected South Asian counties. As stated above, the results of table 1 depict statistical significant relationship between growth and all the explanatory variables, except investment variable (GDI) for Srilanka, which also possesses the expected positive sing. India has the largest coefficient for the GDI as compared to other South Asian countries while Srilanka have the lowest. This result is consistent with the previous studies of growth conducted by Levine and Renelt (1992).

\subsection{Trade Distortion Index}

In Table 2 the results of equation 33 are reported, by including the trade distortion index. This index is developed by David Dollar (1992) which is used to measure the degree of real exchange rate distortions. The value of the index above 100 will imply the trade distortions. The empirical value of this index for South Asian countries, the average value of this index, lies above 100 that is 142, 144, 185 and 237 for India, Pakistan, Bangladesh and Sriklanka, respectively. This result shows that Sriklanaka has the larges level of exchange rate distortions as compared to other South Asian economies. The overall average value higher level of this index for the whole region is 152, which also exhibit that overall higher level of exchange rate. The results of investment (GDI) and knowledge gap (GAP) are also not affected by the inclusion of this variable Dollar in the equation and these variables have maintained their expected signs. Overall this result shows that Pakistan and its neighboring countries economies have high trade barriers in terms of overvalued exchange rate, which could be deterrent to their exports as Well as to economic growth. These results are consistent with the study conducted by Dollar (1992). But our results of the value of the average exchange rate are different to that of Dollar's. He had calculated lower exchange rate distortion magnitudes for South Asian countries, which is below than 100 .

\subsection{Trade Intervention Index}

In Table 3, the regression results of equation 34 include another trade intervention index known as Pitchet Index. This index is measuring the impact of distortions in the trade flows. The sings of all the variables in the equation remain intact even after the inclusion of this variable. The investment variable (GDI) is statically significant for all the countries, except for Srilanka. While this variable is significant for Pakistan, India, and Bangladesh, respectively. One of the possible interpretations of the said case could be that by the inclusion of intervention index might have decreased the supply of imported goods in the economy and also due to the distortion effects, it have become insignificant.

Our results support the notion that in a open economy, in which domestic production requires domestic and imported inputs, trade distortions caused by government policies like tariffs and exchange controls, lower growth significantly over a long period. As, it impedes the supply of imported inputs, thereby, decreasing the productivity of capital accumulation and hence, leading to reduction in the growth rate.

Finally, it came out that by including the trade intervention index in the model, it did not affect the significance of the other variables and their signs remain intact. The catching up hypothesis is also remained valid for all the selected countries but the interventions are making their catching up speed very low. The sensitivity analysis's performance is also quite good which is showing the robustness of the results. The results suggest that intervention level should be brought down for all these countries to make the economies more competitive and for bringing efficiency in their all sectors.

\subsection{Research and Development Expenditures}

In table .4 provides the results of equation 36 by including research and development expenditures in place, of GAP variable. This is another proxy used for measuring the knowledge gap. We could only be able to attain the 
data of number of research and development professional for Srilanka and India, while the data for other South Asian countries is not available. Therefore; the study is limited to these countries only.

The results of the regression for investment variable (GDI) and trade openness is statistical significant and positive for countries, India and Srilanka. The coefficients of R\&D used as a proxy for the catching up affect is negative and statically significant, suggesting that as envisaged by the model, with other things given, countries with larger technological gap will tend to catch up faster to the developed countries. Hence, the notion of catching up hypothesis seems also valid in the case of South Asian countries. The results are supporting the proposition of the new endogenous growth theories, that the developing countries will grow faster than the developed countries and will catch up DCs in the long run. The results of R\&D for South Asian countries indicate that India is converging at faster pace than Srilanka due to larger R\&D base. India had 148 Scientists and engineers per million people in 2005, while Srilanka had only 87 Scientists and engineers in 2005. Pakistan had 92 Scientists and engineers in 2005. All these Figures depict the India's edge in R\&D on other South Asian countries. The coefficient magnitudes are- 1.005 and -0.264 for India and Srilanka, respectively. It indicates that if there is one percent increase in the number of research and development professionals, it will lead to converge India at the rate of $1 \%$ and the Bangladesh at the rate of $0.2 \%$ towards the steady state. The reason for showing high magnitudes of convergence for India could be that it has invested a lot in the research and development. It is not only gaining grounds in the world standard defense production but also marvelously performing in the IT sector.

\section{Conclusion}

The empirical findings support the proposition that controlling other factors, trade liberalizations leads to enhance the economic growth for all the selected countries in the sample. The convergence hypothesis is also holding, as the initial income variable (GAP) and Research and Development variable (RD) are depicting the expected negatives sings that confirms the notion that endogenous growth theory stand binding in thee countries. These South Asian countries exhibit the trend that they will catch the developed countries in the long run.When study touches econometric estimation using time series covers the most important topic of trade liberalization and its impact on economic growth. It is envisaged that foreign trade can make significant contribution to a country's economic growth. Since liberalization is considered as a powerful locomotive of growth. There are conflicting views about it. Some growth models accent potentially negative aspects of trade and recommend that trade promotion be given less weight than production geared to local needs. Finally some models relegate the trade sector to more or less neutral role.

Although there exists some studies on growth in the literature but there are only few which are taking the important relationship between trade liberalization, globalization and economic growth. As per our knowledge there hardly exist any study on the subject matter in the South Asian countries perspective. In the very study we have measured the impact of a wide range of openness measures on economic growth by employing more robust statistically significant techniques for time series analysis in the case of South Asian countries. Besides this, the study also highlighted other sources and contributory factors to economic growth. An endogenous growth model is developed to study the above linkages, mainly the channels through which trade liberalization affects the economic growth. It has also been explored and evidence were provided by Arthur Lewis (1955), of the theory that a country with more open boundaries will have the greater imitation capacity and will imitate, the world technological changes faster as compare to other less imitative capacity countries. These technology follower countries will catch the technology leaders in the long run. Globalization overall and especially trade liberalization will play an important role in this run.

\section{References}

Baldwin, R.E. (2000). Trade and Growth: Still Disagreement about the Relationships. OECD Working Paper No.264, Economics Department. Available at: www.oecd.org/eco/eco

Barro, R.J. (1989). Economic Growth in Cross Section of Countries, Working Paper No. 201, University of Rochester, New Yo

Barro, R.J. and J-W, Les. (1993). International Comparisons of Educational Attainment, Journal of Monterey Economics, 32:3,363-394.

Ben David, D. (1993). Equalizing Exchanging Rate: Trade Liberalization and Income Convergence, Quarterly Journal of Economics, 108, 653-679.

Barnetti, Aymo and Weder, Beatric. (1999). More Open Economies Have Better Govenrments. Available at http://www.unibas.ch/wwz/wifor/staff/bw/survey 
Choksi, A. (1991). Trade Liberalisation Episodes, Basial Blackwell Oxford.

Chudhary, M. Aslam and Ali Shahbaz. (1993). Pakistan's Foreign Dependence, its Capacity for Debt Repayment and Future Prospects, Pakistan Economic and Social Review, 31:3.

Collins, S. and W Park. (1988). External Debt and macroeconomic performance in South Korea, National Bureau of Economic Research, Working paper No. 2596, Cambridge, M.A.

L1oyd, P.J., and MacLaren, Donald. (2000). Openness and Growth in East Asian after the Asian Crisis, Journal of Asian Economics, 11,89-105.

Lewis, W.A. (1955). The Theory of Economic Growth, Allen \& Unwin, London .

Lucas, R.E. (1988). On the Mechanics of Economic Development, Journal of Monetary Economics, 22,3-42.

Romer, D. (1996). Advanced Macroeconomics, McGraw Hill: New York.

S. (1989). Openness, Outward- Orientation, Trade Liberalisation and Economic Performance in Developing Countries, National Bureau of Economic Research, Working Paper No. 2908, Cambridge, M.A.

Table 1. Openness and Economic Growth

DEPENDENT VARIABLE: GDPPC

\begin{tabular}{|l|l|l|l|l|}
\hline \multicolumn{5}{|c|}{ Countries } \\
\hline Variables & Pakistan & India & Srilanka & Bangladesh \\
\hline C & 1.158 & -2.813 & 2.619 & 0.408 \\
& $(1.253)$ & $(-1.643)$ & $(5.567)$ & $(0.451)$ \\
\hline GDI & $1.158^{* * *}$ & $2.843^{* * *}$ & 0.0044 & $2.062^{*}$ \\
& $(1.253)$ & $-(2.133)$ & $-(3055)$ & $(3.328)$ \\
\hline GAP & $-4.542^{*}$ & $-2.044^{* *}$ & $-5.234 *$ & $2.042^{*}$ \\
& $-(4.4538)$ & $(2.198)$ & $-(6.370)$ & $-(3.380)$ \\
\hline TOP & $0.636^{* * *}$ & $1.312^{* *}$ & $1.223 *$ & $2.042^{*}$ \\
& $(1.9215)$ & $(2.198)$ & $(4.794)$ & $(3.825)$ \\
\hline$R^{2}$ & 0.997 & 0.987 & 0.998 & 0.954 \\
\hline DW & 2.310 & 2.686 & 2.398 & 1.921 \\
\hline AR (1) & 0.513 & & 0.522 & 0.843 \\
& $(5.445)$ & & $(7.0571)$ & $(7.859)$ \\
\hline MA (1) & & 0.599 & & -0.451 \\
& & $(4.911)$ & & $-(1.790)$ \\
\hline F Stat & 3604.25 & 523.7803 & 7537.083 & 135.3787 \\
\hline N & 38 & 38 & 37 & 38 \\
\hline
\end{tabular}

Note; The numbers in the parentheses are $t$ values.

*Significant at $1 \%$

** Significant at $5 \%$

$* * *$ Significant at $10 \%$

$\mathrm{C}=$ Constant Term

GDI $=$ Gross Domestic Investment

GAP $=$ Knowledge Gap

$\mathrm{TOP}=$ Trade Openness. 
Table 2. Results for growth Equation 33

Distortions and Economic Growth

Dependent variable: GDPPC

\begin{tabular}{|l|l|l|l|l|}
\hline \multicolumn{5}{|c|}{ Countries } \\
\hline Variables & Pakistan & India & Srilanka & Bangladesh \\
\hline C & 3.055 & -2.050 & 5.218 & 3.245 \\
& $(3.913)$ & $-(1.478)$ & $(6.778)$ & $(4.485)$ \\
\hline GDI & $1.669^{*}$ & $3.223^{* * *}$ & 0.1809 & $1: 503^{* *}$ \\
& $(2.913)$ & $(2.412)$ & $(0.293)$ & $-(2.068)$ \\
\hline GAP & $-9.095^{*}$ & $-2.007^{*}$ & $-10.968^{*}$ & $-9.349^{*}$ \\
& $-(36.291)$ & $-(2.647)$ & $-(9.355)$ & $-(2.844)$ \\
\hline Dollar & $-1.919^{* *}$ & $-0.384^{*}$ & $-0.3003^{* * *}$ & $-1.137^{*}$ \\
& $-(2.081)$ & $-(4.967)$ & $-(1.7814)$ & $-(2.844)$ \\
\hline $\mathrm{R}^{2}$ & 0.996 & 0.992 & 0.997 & 0.949 \\
\hline DW & 2.006 & 1.724 & 1.828 & 1.97 \\
\hline AR (1) & 0515 & 0.656 & 0.865 & 0.929 \\
& $(3.848)$ & $(7.477)$ & $(5.870)$ & $-(15.22)$ \\
\hline MA (1) & & & & -0.641 \\
& & & & $-(3.773)$ \\
\hline F Stat & 3721.7 & 995.9687 & 2169.354 & 120.4022 \\
\hline N & 38 & 37 & 26 & 38 \\
\hline
\end{tabular}

Note: The values in parentheses are $t$ values.

*Significant at $1 \%$

** Significant at 5\%

$* * *$ Significant at $10 \%$

$\mathrm{C}=$ Constant term

GDI $=$ Gross Domestic Investment

$\mathrm{GAP}=$ Knowledge Gap

Dollar $=$ Dollar price Distortion Index 
Table 3. Results for growth Equation 35

Trade intervention and Economic Growth

Dependent variable: GDPPC

\begin{tabular}{|l|l|l|l|l|}
\hline \multicolumn{5}{|c|}{ Countries } \\
\hline Variables & Pakistan & India & Srilanka & Bangladesh \\
\hline C & 0.439 & -1.917 & 4.881 & -0.675 \\
& $(0.7005)$ & $-(1.023)$ & $(9.811)$ & $-(1.213)$ \\
\hline GDI & $1.352^{*}$ & $3.114^{* * *}$ & 0.398 & $2.081^{* *}$ \\
& $(3.244)$ & $(1.724)$ & $(1.063)$ & $(4.403)$ \\
\hline GAP & $-3.019^{*}$ & $-2.230^{*}$ & $-11.442^{*}$ & $-1.943^{* * *}$ \\
& $-(4.114)$ & $-(2.109)$ & $-(10.178)$ & $-(3.977)$ \\
& & & -1.686 & \\
& & & $-(1.561)$ & \\
\hline Dollar & $-6.45 \mathrm{E}-11$ & $-1.82 \mathrm{E}-11$ & 0.997 & $-6.45 \mathrm{E}-11$ \\
& $-(0.1933)$ & $-(0.414)$ & & $-(0.1933)$ \\
\hline R ${ }^{2}$ & 0.997 & 0.986 & 1.819 & 0.943 \\
\hline DW & 2.102 & 2.105 & 0.863 & 1.79 \\
& & & $(9.491)$ & \\
\hline AR (1) & 0.566 & 0.654 & -0.182 & 0.652 \\
& $(6.344)$ & $(5.380)$ & $-(0.851)$ & $(7.832)$ \\
\hline MA (1) & & & -0.182 & \\
\hline F Stat & 1019.609 & 140.4278 & 2747.370 & 18.4532 \\
\hline N & 38 & 37 & 38 & 37 \\
\hline
\end{tabular}

Note: The values in parentheses are $t$ values.

* Significant at $1 \%$

** Significant at $5 \%$

***Significant at $10 \%$

$\mathrm{C}=$ Constant Term

GDI $=$ Gross Domestic Investment

GAP $=$ Knowledge Gap Pitchet $=$ Trade Intervention Index 
Table 4. Results for growth Equation 37R \& D and Economic Growth Dependent variable: GDPPC

\begin{tabular}{|l|c|c|}
\hline \multicolumn{3}{|c|}{ Countries } \\
\hline Variables & India & Srilanka \\
\hline C & -4.343 & 0.688 \\
& $-(2.4613)$ & $(0.899)$ \\
\hline GDI & $3.949^{* *}$ & $2.347^{*}$ \\
& $(2.384)$ & $(5.086)$ \\
\hline RD & $-1.005^{* *}$ & $-1.587^{*}$ \\
& $-(2.305)$ & $-(3.261)$ \\
\hline TOP & $1.049 * * *$ & $0.264^{* * *}$ \\
& $(1.649)$ & $(1.7687)$ \\
\hline R & 0.986 & 0.955 \\
\hline DW & 2.183 & 1.972 \\
\hline AR $(1)$ & 0.785 & \\
& $(7.462)$ & 134.372 \\
\hline F Stat & 585.669 & 38 \\
\hline N & 23 & \\
\hline
\end{tabular}

Note: The values in parentheses are $\mathrm{t}$ values.

* Significant at $1 \%$

** Significant at $5 \%$

$* * *$ Significant at $10 \%$

$\mathrm{C}=$ Constant Term

TOP $=$ Trade Openness

GDI $=$ Gross Domestic Investment

$\mathrm{RD}=$ No of Scientists and engineers engaged in research and development activity 